Int. J. Electrochem. Sci., 14 (2019) 6643 - 6657

\title{
Synthesis and Electrochromic Properties of Two Random Copolymers Containing Benzotriazole, Benzothiadiazole as Electron Acceptors and Benzodithiophene or Indacenodithiophene as Electron Donors
}

\author{
Shaowen Pei ${ }^{1}$, Xiuping Jü, Jinsheng Zhao ${ }^{2, *}$, Yan Wang, Hongmei Du ${ }^{2, *}$ \\ ${ }^{1}$ Shandong Key Laboratory of Chemical Energy Storage and Novel Cell Technology, Liaocheng \\ University, Liaocheng, 252059, P. R. China. \\ ${ }^{2}$ Department of Chemistry and Chemical Engineering, Liaocheng University \\ ${ }^{3}$ Colledge of Dongchang, Liaocheng University, Liaocheng University \\ Corresponding author, Tel: +86-635-8539607; Fax: +86-635-8539607. \\ *E-mail: j.s.zhao@163.com
}

doi: $10.20964 / 2019.07 .23$

Received: 2 March 2019/ Accepted: 22 April 2019 / Published: 10 June 2019

Two random copolymers, poly (benzotriazole-indacenodithiophene-benzothiadiazole) (PBTIDBD) and poly (benzotriazole-benzodithiophene-benzothiadiazole) (PBTBDBD) were synthesized and characterized by electrochemistry, spectroelectrochemistry, electrochromic switching, colorimetry and thermal gravimetric analysis. For PBTIDBD, the color of film changed from rosybrown in neutral state to transparent lightgrey in oxidized state. The band gap calculated according to the spectroelectrochemistry data is $1.86 \mathrm{eV}$, and the response time, optical contrast, coloration efficiency at $1560 \mathrm{~nm}$ are $1.04 \mathrm{~s}, 62.1 \%, 276.29 \mathrm{~cm}^{2} \cdot \mathrm{C}^{-1}$, respectively. And, for PBTBDBD, its color changes from rosybrown to transparent grey as it was fully oxidized. The band gap is $1.68 \mathrm{eV}$, and the response time, optical contrast, coloration efficiency at $1560 \mathrm{~nm}$ are $2.68 \mathrm{~s}, 62.4 \%, 193.31 \mathrm{~cm}^{2} \cdot \mathrm{C}^{-1}$, respectively. Both copolymers are stable at a high temperature, and the decomposition temperature of PBTIDBD and PBTBDBD are $463{ }^{\circ} \mathrm{C}$ and $326^{\circ} \mathrm{C}$. Both copolymers can be good candidates for electrochromic application.

Keywords: conducting polymers; indacenodithiophene; benzotriazole; benzothiadiazole; benzodithiophene. 
(C) 2019 The Authors. Published by ESG (www.electrochemsci.org). This article is an open access article distributed under the terms and conditions of the Creative Commons Attribution license (http://creativecommons.org/licenses/by/4.0/). 